\title{
Infrastructure issues for implementation of portable computer use in schools
}

\author{
Anne McDougall \\ Faculty of Education \\ Monash University, Clayton Victoria 3168, Australia \\ Tele + 6139905 2790; Fax + 61399052779 \\ E-mail: Anne.McDougall@education.monash.edu.au
}

\begin{abstract}
It has been suggested that the use of battery operated portable notebook computers offers solutions for IT implementation in developing countries, especially where electricity supplies are not reliable. This paper raises a number of issues which need to be addressed when implementing portable computers in school settings and provides strategies based on Australian schools' experiences. The information should be useful to decision makers in developing countries.
\end{abstract}

\section{Keywords}

Developing countries, future developments, hardware, infrastructure, portable computers

\section{INTRODUCTION}

This paper looks at infrastructure issues in the implementation of portable computer use in schools. It is based on the introduction and use of portable computers in Australian schools and provides information for decision-makers in developing countries where this approach to school computing is under consideration.

The first projects involving extensive use of portable computers in Australian schools began in 1990. Now, although the proportion of schools using portable computers is still a minority of Australian schools, teachers and administrators

Capacity Building for IT in Education in Developing Countries

G. Marshall \& M. Ruohonen (Eds.)

(1) 1998 IFIP. Published by Chapman \& Hall 
have considerable experience in the establishment and maintenance of portable computer use.

The experiences of a number of schools should prove instructive for educators in developing countries. After looking at the major reasons for adopting portable computers, the paper considers approaches to the provision and funding of portable computers for school use, the need for technical support, issues related to battery life and recharging, the need for additional desktop computers and other hardware in a school, and teacher support for integration of portable computers.

\section{Portable computers}

The term portable computers refers to machines that are small and can be carried with one hand - in contrast to the large desktop machines. Portable computers run on power from batteries or with a mains power adaptor. The screen is an integral part of the case of the computer, not a separate monitor. Portable computers include the earliest laptop computers, the more recently introduced notebooks, smaller palmtops and some low cost dedicated word processors (NCET, 1992). Australian schools use notebook computers, machines roughly the size and weight of a telephone directory, and equipped with a full size keyboard and a screen contained under a folding lid.

\section{Reasons for school use of portable computers}

Portable computers were introduced into Australian schools because educators believe that students must be equipped for a technology rich future. Adopting schools, especially nongovernment schools where student tuition fees are the major source of income, are also cognizant of marketing issues. The motivation for most of the portable computer initiatives can be summarised by David Loader, Principal of the Methodist Ladies' College, the first school to introduce compulsory notebook computer acquisition by its students.

'The emphasis is ... on developing a new curriculum that is relevant in a culture that is being transformed by technology. ... The school is also mindful of the market situation that will determine enrolments'.

$$
\text { (Loader, p. 9, 1993) }
$$

Where portable computers are being used extensively the resulting changes in curriculum and school culture have often been considerably greater than initially anticipated. For example, Grasso says,

'The new seemingly small and tentative step of introducing personal laptops into some classrooms in 1990 has mushroomed into the development of an entirely different school culture in which technology is not a novelty, but an all-pervasive influence. It has become a medium for constructing one's own learning which is taken for granted in much the 
same way as pens and paper were previously. ... The school became a community of learners, where cooperative and collaborative learning became the norm'.

(Grasso, 1993)

Commenting on the benefits of portable computer use, Colin Potts, Director of Computing at Trinity Grammar School, Melbourne, lists the following advantages:

- Teachers know that their students will have ready access to the technology and can plan classes accordingly.

- Students can take advantage of the technology at the time it is needed and at the place it is needed.

- Students have access to the technology continually. Work started at school can be continued at home.

- Through regular use of the technology, students develop advanced skills in a meaningful context and through continual reinforcement.

- Student ownership of notebook computers relieves the school of the need to regularly upgrade and extend their hardware facilities.

- Mobile computers facilitate delivery of cross-curriculum computing (1997).

Potts's views would be shared by teachers in similar positions and by administrators and parents at most other adopting schools. In general the schools consider the benefits to be worth the costs of adoption of portable computer use.

\section{Provision and funding of computers}

In a considerable proportion of schools implementing extensive portable computer use, the students' parents are required to buy or lease their own computers. The school specifies the brand and type of computer and, in many cases, the software to be installed on the machine. A major advantage of this arrangement is that students can use the computers at any time, at school or at home. Standardisation of hardware and software facilitates maintenance, enables bulk purchase of software and makes teacher in-service training more efficient. A possible disadvantage for some students is that the machine required by the school might be incompatible with a computer already in the students' homes.

Although requiring students to provide their own computers does relieve the school of the cost of the actual machines, personnel with appropriate knowledge are needed in the school to arrange bulk purchases or lease agreements, install specified software, distribute the computers and keep records of maintenance, inventories and other transactions. In schools with extensive use of portable computers, where the curriculum is quite dependent on portable computer use, loan machines might be provided for students whose computers are away for repairs (Symes, 1997). Large monitors are also needed at schools for class display of work generated on the smaller machines regularly used by the students.

While some schools require students to purchase their computers, other schools provide the portable computers for students' use. Often these are in class sets for borrowing for limited times and, sometimes, for longer term individual use. The arrangement gives students greater access to computers and greater flexibility than 
is generally available with desktop machines but it requires some forward planning by teachers and does not provide the unlimited access that student machine ownership does.

Provision of portable computers for teacher use is important for successful adoption of a school portable computer programme. Generally the schools have provided either computers or financial assistance with computer purchase for staff members.

Insurance is another issue to be addressed as the situation for portable computers is more complex than is the case for desktop machines. Students' home use of the equipment must be covered. Transit between school and home must also be considered and transit is probably the time of greatest risk. Screen breakage has been a problem for some schools and special padded carry bags are used by some students. It is thought wise to avoid labels on the carry bags that identify the contents as computers, as this can invite theft or vandalism so some schools prefer students to carry their computers inside a bigger school bag for these reasons.

\section{Technical support}

All the schools adopting portable computers for student use have learned that technically-skilled personnel must be allocated time to provide technical support for students and teachers using the portable machines. The extent of this support varies - from the reduction of the teaching load of a regular teacher with appropriate skills through combinations of technicians on site to fix small problems and a courier service to the supplier for more major repairs (Fallshaw, 1993) to dedicated centres with several technical and administrative staff to handle repairs, maintenance, purchasing, software installation, distribution of machines, equipment bookings, classroom support and other services (Symes, 1997). Some schools with extensive portable computer use also provide a 'help desk' service for teachers and students. The schools say that personal and prompt assistance must be available if the technology is to support and not hinder the educational endeavours of the school (Symes, 1997).

\section{Battery power for portable computers}

Since the use of portable computers has been raised as a possible solution for school-based computing in developing countries where electricity supplies may be unreliable, the issue of battery power for portable computers warrants attention. While batteries can provide power for computing independent of mains electricity at the time of use of the machine, battery life is finite and the batteries do need recharging using mains electricity.

The batteries in the earliest laptop computers lasted only a few hours before needing recharging and ingenious systems for recharging during storage were devised in some schools. De Figueiredo (1991) described the construction of large boxes containing recharging plugs connected to mains power and used for storing and recharging class sets of portable computers. These 'computer coffins' were mounted on trolleys so they could be wheeled to classrooms where the computers were needed.

In other schools special storage lockers with recharging plugs have been built for the storage and recharging of individual students' computers when they were not needed in class. Schools may buy, and keep charged, supplies of spare batteries so 
that a student whose battery runs low in class can simply exchange the low one for a fully-charged spare battery.

Underlying all of these strategies is the need for a minimum level of reliability of mains electricity supply, at least for overnight recharging of batteries. As the technology develops the charged life of batteries is lengthening markedly; however battery-operated computers do not give complete independence from mains electricity.

\section{Desktop computers, printers and other hardware}

The adoption of portable computer use has not eliminated the need for schools to purchase desktop machines and other hardware. Many useful computing activities are not easily done on the portable computer. For example, relatively few schools have facilities in all classrooms for connecting portable computers to the Internet so this is more often done using desktop machines. Printers, scanners and other peripherals are generally provided in classrooms and in libraries or resource centres for use with the portable computers.

\section{Teacher support}

All of the Australian initiatives have been accompanied by staff anxiety, due either to technical problems or to stress from the increased workload and amount of change that seems inevitably to accompany innovation. This anxiety can be minimised by provision by the school of support for the teachers as the innovation is planned and implemented.

Support occurs in several ways - providing or subsidising teachers' purchase of their own portable computers, articulating the purpose and philosophy of the initiative, providing time to work with the new equipment and software before using it in classrooms, supporting classroom based technical problems, providing teachers with opportunities to attend workshops, courses and conferences, and facilitating the development of networks of people with expertise available to help (McDougall and Betts, 1996).

With good opportunities for professional development and adequate school and classroom support, it is clear that many teachers, including teachers who may have had relatively little confidence with classroom computing previously, can become creative and effective users of the technology. Conversely, implementation of portable computer use in a school without such teacher support is unlikely to be genuinely successful in terms of student learning.

Many issues need to be addressed in the implementation of portable computer use in school settings. Australian schools have developed strategies to address the issues and have accumulated experience in providing and funding of portable computers, devising ways to technically support the innovation, creating novel solutions for providing battery power for the machines, addressing the need for additional hardware in a school and meeting teacher support needs.

Another issue, which will be only briefly addressed in this discussion, is the question of what impact portable computer use has on schools' curricula. Although 
little research has been conducted on the long-term effects of portable computer use, two publications by the present author provide a preliminary analysis of the most recently observed outcomes (McDougall, 1995; McDougall and Betts, 1997). Reported outcomes include improved IT knowledge and skills, increased cooperative work and peer learning, more flexible approaches to problem solving, substantial changes in classroom organization and management, increased student responsibility for learning, and parental reports of improved attitudes to homework.

It is difficult for the writer to assess how directly the experiences of implementation of portable computer use in predominantly urban schools in Australia would transfer to the variety of school situations which exist in developing countries. Clearly there will be some major differences in contexts and settings, and it is expected that readers from different countries will respond to the ideas in the paper in different ways. However it is hoped that this account of the experiences and strategies used in Australia will provide information useful for those involved in relevant decision making processes in other countries.

De Figueiredo, J. (1991) Selection, installation and use of laptop computers. Proceedings of the 1991 CEGV Conference. Computing in Education Group of Victoria, Melbourne, Australia.

Fallshaw, M. (1993) Using laptops in schools - the administrative implications, in Reflections of a Learning Community: Views on the Introduction of Laptops at $M L C$. (eds. I. Grasso and M. Fallshaw), Methodist Ladies' College, Kew, Victoria, Australia.

Grasso, I. (1993) Foreword, in Reflections of a Learning Community: Views on the Introduction of Laptops at MLC. (eds. I. Grasso and M. Fallshaw), Methodist Ladies' College, Kew, Victoria, Australia.

Loader, D. (1993) Reconstructing an Australian school, in Reflections of a Learning Community: Views on the Introduction of Laptops at MLC. (eds. I. Grasso and M. Fallshaw), Methodist Ladies' College, Kew, Victoria, Australia.

McDougall, A. (1995) Integration of portable computers into Australian classrooms: Issues and outcomes, in Integrating Information Technology into Education. (eds. D. Watson and D. Tinsley), Chapman \& Hall, London.

McDougall, A. and Betts, J. (1996) Teacher professional development in a technology immersion school, in Information Technology: Supporting Change Through Teacher Education. (eds. D. Passey and B. Samways), Chapman \& Hall, London.

McDougall, A. and Betts, J. (eds.) (1997) Learning with the Media of Their Time. Computing in Education Group of Victoria, Melbourne, Australia.

NCET (1992) Choosing and Using Portable Computers. National Council for Educational Technology, Coventry, U.K.

Potts, C. (1997) Laptops in schools. TISP Online, 2(1), Technology in Schools Program, The University of Melbourne, Melbourne, Australia, 8.

Symes, E. (1997) Computer and audio visual engineers, in Learning with the Media of Their Time. (eds. A. McDougall and J. Betts), Computing in Education Group of Victoria, Melbourne, Australia. 


\section{BIOGRAPHY}

Anne McDougall has worked as a secondary teacher in Australia and then as a computer programmer in the USA. In 1973 she took up a research fellowship in computer education at the University of Melbourne, developing software for use in undergraduate teaching. Her subsequent lecturing and research work has been concerned with computers and learning at secondary and primary school levels. She is now Associate Professor in Educational Computing at Monash University. Her recent publications include Choosing and Using Educational Software co-authored with David Squires and Learning with the Media of TheirTtime co-authored with Jenny Betts. 